\title{
PRELIMINARY STUDY ANALISIS BEBAN KERJA MENTAL DI INDUSTRI KREATIF
}

\author{
Muhammad Ragil Suryoputro ${ }^{1}$, Retno Gumilar ${ }^{2}$, Nashtiti Aliafari ${ }^{3}$ \\ Jurusan Teknik Industri, Fakultas Teknologi Industri, Universitas Islam Indonesia, ${ }^{1,2,3)}$ \\ Jl.Kaliurang Km.14,5 Sleman, Yogyakarta 55584. \\ E-Mail : ragil.suryoputro@uii.ac.id ${ }^{l}$
}

\begin{abstract}
This research was the preliminary study analysis for the mental workload for creative industries. There were issues of productivity during the work performed by the employee. This paper aimed to measure the mental workload based on three job positions for two batik creative industries. The method that used is NASA-TLX, which involved 6 employees. There are variations based on three job positions (production, administrative and packaging) in both industries. The mental workload obtained during the research is 41.67 for UKM Batik 1 and 70.44 for UKM Batik 2. In overall, both batik industries having high mental workload, only in small portion is in medium position. The highest mental workload was for production process in UKM Batik 2. The further research should be conducted on improving the work system design for all positions, especially on production process.
\end{abstract}

Keywords : Mental Workload, NASA-TLX, Productivity, UKM / Small Medium Enterprises, Creative Industries.

\section{PENDAHULUAN}

Industri kreatif merupakan industri yang mengedepankan nilai budaya dan seni yang merupakan salah ciri khas dan keunikan dari suatu daerah geografis maupun politis tertentu. Dalam sebuah Negara, terdapat beragam industri kreatif yang mendukung perekonomiannya. Indonesia merupakan Negara kepulauan yang memiliki beragam kekayaan alam dan budaya yang terkenal di dunia, baik berupa produk budaya asal, maupun produk akulturasi. Salah satu kekayaan budaya Indonesia yang terkenal adalah kerajinan, contohnya batik. Dirjen Kementrian Perindustrian menyatakan bahwa ekspor batik dan produk batik meningkat sebesar $25.7 \%$ di tahun 2015 atau berkisar 178 juta USD (http : // www.suara.com / bisnis / 2016 / 10 / 03 / 194113 / ekspor-batikindonesia-tahun-2015-178-juta-dolar-as).

Desainer batik Chitra Subiyakto juga menekankan bahwa batik berakar budayakan Indonesia (http : // www.thejakartapost.com /life / 2016 / 10 / 04 / 12-local-designers-participate-inbatik-fashion-week.html). Hal ini menegaskan bahwa industri kreatif batik sangat penting bagi keberlangsungan budaya, sekaligus dapat meningkatkan perekonomian Indonesia secara luas. Namun, seiring dengan perkembangan batik, yang merupakan warisan budaya bangsa yang semakin terkenal, motif yang beragam dan kaya, sekaligus merupakan komoditas bernilai, industri kreatif batik memiliki sejumlah tantangan, seperti kesenjangan antara perajin dan pengusaha (http : // www.kemenperin.go.id / artikel / 10159 / Perajin-dan-Pengusaha-BatikMasih-Senjang). Batik, sebagai jati diri bangsa merupakan pengikat untuk pariwisata Indonesia, dimana diperkirakan pada tahun 2019 sektor pariwisata merupakan penyumbang devisa terbesar Negara (http://obsessionnews.com/devisaterbesar-indonesia-2019-dari-pariwisata/).

Perubahan lingkungan bisnis dan kompetisi usaha di sektor industri kreatif berupa batik seringkali menuntut organisasi meningkatkan kinerja sehingga pengoperasiannya dapat berjalan efektif dan efisien. Tujuan utamanya agar organisasi tersebut tetap mendapatkan pelanggan dan mempertahankan keberlanjutan usahanya. Demikian juga dengan sumber daya 
manusia, baik perajin maupun pengusaha, yang harus senantiasa meningkatkan kinerjanya sehingga dapat bersaing dengan tetap memberikan pelayanan terbaik bagi pelanggan (Hendrawan, et al., 2012).

Setiap pekerja memiliki beban kerja dari pekerjaan yang dilakukan oleh pekerja tersebut, dikarenakan pada saat melakukan pekerjaan semua pekerja mengeluarkan usaha untuk memenuhi tuntutan dari pekerjaannya. Beban kerja dapat berupa beban kerja fisik dan beban kerja mental. Beban kerja fisik dapat berupa beratnya pekerjaan seperti mengangkat, merawat, mendorong. Sedangkan beban kerja mental dapat berupa sejauh mana tingkat keahlian dan prestasi kerja yang dimiliki individu dengan individu lainnya (Manuaba, 2000 dalam Tarwaka, 2004).

Kedua beban kerja (fisik dan mental) tersebut perlu dipertimbangkan dalam melakukan pengelolaan SDM (Hancock, 1988). Jex (1988) mendefinisikan beban kerja mental sebagai perbedaan dari tuntutan kebutuhan beban kerja dalam sebuah tugas terhadap kapasitas beban maksimum pada kondisi mental seseorang saat termotivasi. Tingginya tingkat beban kerja mental pekerja dapat mempengaruhi produktivitasnya. Produktivitas pekerja akan mempengaruhi produktivitas dari sebuah perusahaan atau organisasi. Sehingga dibutuhkan untuk mengukur beban kerja yang hasilnya dapat sebagai dasar dalam memberikan rekomendasi untuk mencegah permasalahan seperti menurunnya produktivitas.

Penelitian ini akan berfokus pada beban kerja mental yang dirasakan oleh pekerja dalam menyelesaikan pekerjaannya. Terdapat beberapa metode untuk menghitung Beban Kerja Mental, antara lain SWAT, NASA-TLX, RSME, dan Modified Cooper Harper Scaling. NASATLX adalah metode rating multidimensional yang mampu mengukur secara keseluruhan beban kerja mental berdasarkan bobot rata-rata dari 6 subskala yaitu Mental Demands, Physical Demands, Temporal Demands, Own Performance,
Effort dan Frustation (Hart dan Staveland, 1988). Metode ini memiliki tingkat sensitivitas yang baik karena pengukurannya ditinjau dari 6 subskala dan menyeluruh (Rubio, Diaz, Martin, \& Puente, 2004). Rating scale mental effort (RSME) merupakan metode pengukuran beban kerja subyektif dengan skala tunggal. Dikembangkan oleh Zijlstra dkk (Zijlstra \& Van Doorn, 1985; Zijlstra \& Meijman, 1989; Zijlstra 1993; dan de Waard, 1996). Metoda SWAT merupakan multidimensional scale. Dalam model SWAT, performansi kerja manusia terdiri dari tiga dimensi ukuran beban kerja yang dihubungkan dengan performansi, yaitu :Time Load, Mental effort, dan Psychological stress (Reid \& Nygren, 1988). Responden diminta untuk memberikan tanda pada skala $0-150$ dengan deskripsi pada beberapa titik acuan (anchor point).

Pada penelitian ini akan digunakan metode NASA-TLX karena NASA-TLX sendiri merupakan metode yang mempunyai tingkat akurasi paling tinggi karena mempunyai indikator yang rinci serta dapat digunakan untuk banyak pekerjaan di dunia kerja. Penelitian ini akan mengambil data pada UKM (Usaha Kecil Menengah) dari industri kreatif batik, UKM batik yang biasanya dikerjakan secara keluarga ataupun hubungan rekan kerja ini terbagi menjadi bagian-bagian yang sederhana, yaitu bagian produksi, administrasi, dan pengemasan. Dengan menggunakan NASA-TLX diharapkan hasil yang didapatkan merupakan beban kerja mental yang sesuai untuk Industri yang dituju (Puspawardhani et.al., 2016).

Produksi pada UKM batik lebih ke pembuatan baju dan konveksi lainnya. Kemudian bagian administrasi pada UKM batik yang diambil datanya merupakan penjaga kasir yang sekaligus sebagai pengurus adminitrasi tentang kain yang harus dibeli untuk bahan baku, bahan dan alat pembuatan dan lain-lain. Kemudian bagian pengemasan lebih ke bagian finishing dari proses produksi batik 
tersebut. Pada pengambilan data ini akan diukur besarnya beban kerja mental dari setiap pekerja pada bagian produksi, administrasi dan pengemasan pada UKM batik.

Oleh karena itu, penelitian ini bertujuan untuk mengukur beban kerja mental menggunakan NASA-TLX pada para pekerja (produksi, administratif dan pengemasan) di dua UKM industri kreatif Batik. Setelah menilai beban kerja mental di industri kreatif batik masing-masing secara terpisah, peneliti akan membandingkan beban kerja mental ketiga tipe pekerjaan tersebut untuk kedua industri kreatif tersebut. Perbandingan tersebut dibutuhkan untuk meneliti seberapa besar perbedaan dan tipe pekerjaan yang memiliki faktor dominan. Selanjutnya akan diberikan rekomendasi untuk mencegah dan mengontrol stress akibat kerja.

\section{TINJAUAN PUSTAKA}

Beban kerja dipengaruhi oleh dua faktor, yaitu faktor eksternal dan faktor internal. Berdasarkan Tarwaka (2004), faktor - faktor yang mempengaruhi beban kerja pekerja adalah :

\section{a. Faktor Eksternal}

Faktor eksternal adalah beban yang berasal dari luar tubuh pekerja, seperti tugas fisik, organisasi pekerja dan lingkungan kerja baik fisik maupun hubungan antar pekerja.

Tugas - tugas yang bersifat fisik, seperti stasiun kerja, tata ruang, tempat kerja, alat dan sarana kerja, kondisi kerja, sikap kerja, dan tugas-tugas yang bersifat psikologis, seperti kompleksitas pekerjaan, tingkat kesulitan, tanggung jawab pekerjaan.

Organisasi kerja, seperti lamanya waktu bekerja, waktu istirahat, shift kerja, kerja malam, sistem pengupahan, model struktur organisasi, pelimpahan tugas dan wewenang.

Lingkungan kerja adalah lingkungan kerja fisik, lingkungan kimiawi, lingkungan kerja biologis dan lingkungan kerja psikologis.

b. Faktor Internal

Faktor Internal adalah faktor yang berasal dari dalam tubuh pekerja itu sendiri sebagai hasil reaksi dari beban kerja / faktor eksternal. Faktor internal termasuk faktor somatis dan faktor psikologis. Faktor somatis meliputi gender, usia, ukuran tubuh, status nutrisi / kadar gizi, dan kondisi kesehatan. Sedangkan faktor psikologis dapat berupa motivasi, persepsi, kepercayaan, keinginan dan kepuasan.

Definisi beban kerja adalah sejumlah target pekerjaan atau target hasil yang harus dicapai dalam satuan waktu tertentu (berdasarkan Kepmenpan No.Kep/ 75 / M.PAN / 2004 - http : // sukabumikota.kemenag.go.id / file / dokumen / D001020.pdf). Menurut Tayyari \& Smith (1997), beban kerja atau kapasitas kerja fisik berhubungan dengan kapasitas maksimum dari sistem fisiologi dalam menghasilkan energi untuk kerja otot. Untuk orang normal, beban kerja berhubungan langsung dengan sistem kerja jantung dalam menyediakan oksigen untuk kerja otot dan untuk membuang limbah metabolisme.

Teknik pengukuran beban kerja perlu mempertimbangkan karakteristik berikut: sensitivitas, kemampuan mendiagnosa, kemampuan menyeleksi, rendah gangguan, kehandalan, dan kemudahan penggunaan. The National Aeronautics and Space Administration Task Load Index (NASATLX) telah memenuhi kriteria - kriteria tersebut (Rubio, Díaz, Martín, \& Puente, 2004). NASA-TLX dikembangkan oleh Sandra G. Hart dari NASA-Ames Research Center dan Lowell E. Staveland dari Universitas San Jose State pada tahun 1988 (Hart dan Staveland, 1988). NASA-TLX merupakan teknik pengukuran dan analisa subjektif untuk beban kerja mental dalam kerangka multi dimensi untuk mendapatkan skor keseluruhan berdasarkan rata - rata bobot dalam enam sub skala: Mental 
Demand-Kebutuhan Mental (MD), Physical Demand-Kebutuhan Fisik (PD), Temporal Demand-Kebutuhan Waktu (TD), Performance-Performansi (OP), EffortUsaha (EF), dan Frustration Level-Tingkat Frustasi (FR). Penggunaan keenam dimensi tersebut untuk menghitung skor total beban kerja keseluruhan diharapkan dapat mengurangi variabilitas antar subyek, relative dibandingkan dengan beberapa penilaian dimensi yang ada, sekaligus menbuat diagnosa informasi terhadap sumber-sumber beban kerja.

Berdasarkan penelitian sebelumnya yang dilakukan oleh Miranti Siti Astuty, Caecillia S.W, Yuniar pada tahun 2012 untuk menganalisa beban kerja mental yang dirasakan masinis Daop II Bandung yang menjalani dinasan kereta jarak dekat (Bandung - Padalarang, BandungCicalengka) dan kereta jauh (BandungBanjar, Bandung-Jakarta). Nilai Score rata rata NASA-TLX yang diperoleh untuk dinasan jarak dekat yaitu $71,7 \%$, dan pada dinasan jarak jauh 82,7\%, serta adanya perbedaan faktor yang mempengaruhi beban kerja mental masinis pada dinasan kereta jarak dekat dan jarak jauh, meliputi: mental demand dan effort. Faktor dominan yang mempengaruhi beban kerja masinis pada saat menjalani dinasan jarak jauh adalah mental demand dan physical demand (Astuty, et.al. 2012).

Jurnal berikutnya dengan yang ditulis oleh Raras Mayang dan Sri Gunani Partiwi, meneliti terhadap empat kali perubahan statuta dan penyesuaian mengenai Organisasi Tata Kelola (OTK), membuat pihak ITS harus melakukan reformasi birokrasi dan reformasi organisasi untuk mengembangkan masa depan ITS yang menyebabkan beban kerja yang ditanggung oleh setiap karyawan di setiap bidang tidak sesuai dengan jumlah karyawan pada bidang itu sendiri. Hasil dari perhitungan beban kerja mengindikasikan terdapat kelebihan beban kerja yang diterima karyawan. Selain itu, perhitungan beban kerja mental menggunakan NASA-TLX menghasilkan bahwa beban kerja mental pengelola jurusan terbesar juga dialami oleh sekretaris jurusan dengan nilai rata - rata WWL sebesar 84, dan, pada karyawan dialami oleh jabatan juru beli dengan nilai rata-rata WWL sebesar 87 (Arsi dan Partiwi, 2014).

\section{METODOLOGI PENELITIAN}

Penelitian ini menggunakan metode penelitian studi lapangan. Studi lapangan dilakukan dengan cara mencari data langsung ke UKM Industri Kreatif. Metode pengolahan data menggunakan NASATLX. Objek penelitian adalah dua UKM Industri Kreatif Batik.

Dalam penelitian ini, pengumpulan data yang digunakan adalah pengumpulan data primer dan sekunder. Tahapan pertama peneliti melakukan study literature yaitu mempelajari secara teori tentang materi yang akan diteliti baik lewat buku maupun penelitian sebelumnya (data sekunder). Kemudian peneliti melakukan pengambilan data dengan cara memberikan kuesioner pembobotan dan rating faktor kepada ketiga responden untuk masing - masing UKM Industri Kreatif (data primer). Kemudian setelah data terkumpul selanjutnya dilakukan perhitungan nilai produk, WWL, dan rata - rata WWL. Setelah memperoleh nilai tersebut maka peneliti akan mendapatkan skor NASA-TLX. Dari skor NASA-TLX itu peneliti dapat memberikan analisis dan rekomendasi yang sesuai.

\section{PEMBAHASAN DAN HASIL}

\subsection{Karakteristik Operator}

Setelah dilakukan pengambilan data pada dua UKM Batik. Didapatkan 3 operator yang masing - masing terbagi menjadi 3 bagian, yaitu bagian produksi, bagian administrasi, dan bagian pengemasan. dua orang merupakan karyawan laki - laki dan empat orang merupakan karyawan perempuan. Variasi umur antara 19 tahun hingga 43 tahun. 
Tabel 3 Nilai Produk

\begin{tabular}{|c|c|c|c|c|c|c|c|c|c|c|c|c|}
\hline \multirow{2}{*}{$\begin{array}{c}\text { Obyek } \\
\text { Penelitian }\end{array}$} & \multicolumn{12}{|c|}{ Indikator } \\
\hline & $\begin{array}{c}\text { MD } \\
1\end{array}$ & $\begin{array}{c}\text { PD } \\
1\end{array}$ & $\begin{array}{c}\text { TD } \\
1\end{array}$ & $\begin{array}{c}\text { OP } \\
1\end{array}$ & $\begin{array}{c}\text { EF } \\
1\end{array}$ & $\begin{array}{c}\text { FR } \\
1\end{array}$ & $\begin{array}{c}\text { MD } \\
2\end{array}$ & $\begin{array}{c}\text { PD } \\
2\end{array}$ & $\begin{array}{c}\text { TD } \\
2\end{array}$ & $\begin{array}{c}\text { OP } \\
2\end{array}$ & $\begin{array}{c}\text { EF } \\
2\end{array}$ & $\begin{array}{c}\text { FR } \\
2\end{array}$ \\
\hline Produksi & 100 & 50 & 280 & 80 & 270 & 30 & 210 & 270 & 180 & 140 & 160 & 140 \\
\hline Administrasi & 60 & 60 & 20 & 40 & 200 & 60 & 210 & 50 & 280 & 280 & 120 & 80 \\
\hline Pengemasan & 160 & 80 & 20 & 30 & 120 & 150 & 60 & 350 & 80 & 160 & 280 & 120 \\
\hline
\end{tabular}

\subsection{Data Pengolahan Nilai NASA-TLX}

Data Pengolaha Nilai NASA-TLX di dapatkan untuk masing - masing UKM Industri Kreatif adalah sebagai berikut :

Berdasarkan data kuesioner, pembobotan didapatkan data sebagai berikut (Tabel 1).

Tabel 1 Nilai Pembobotan

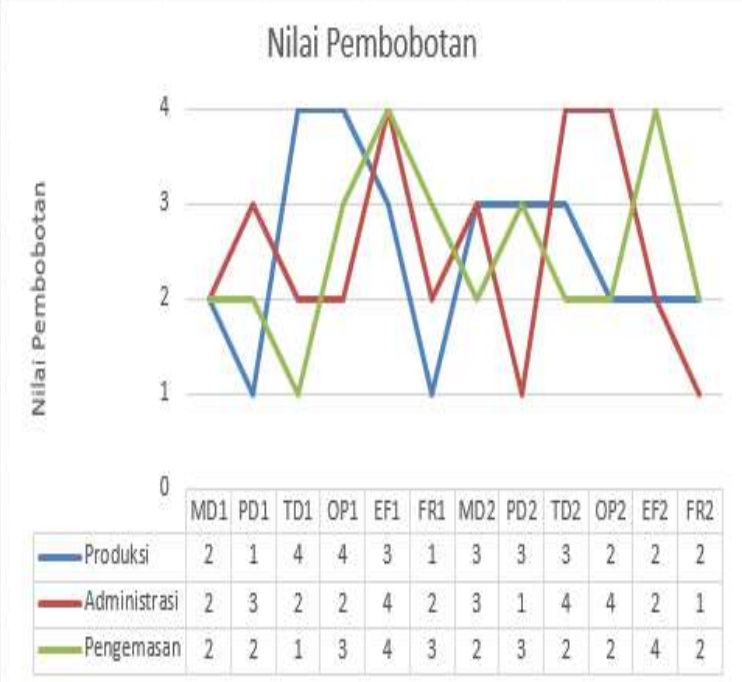

Berdasarkan data kuesioner, Rating di dapatkan data sebagai berikut (Tabel 2).
Tabel 2 Nilai Rating

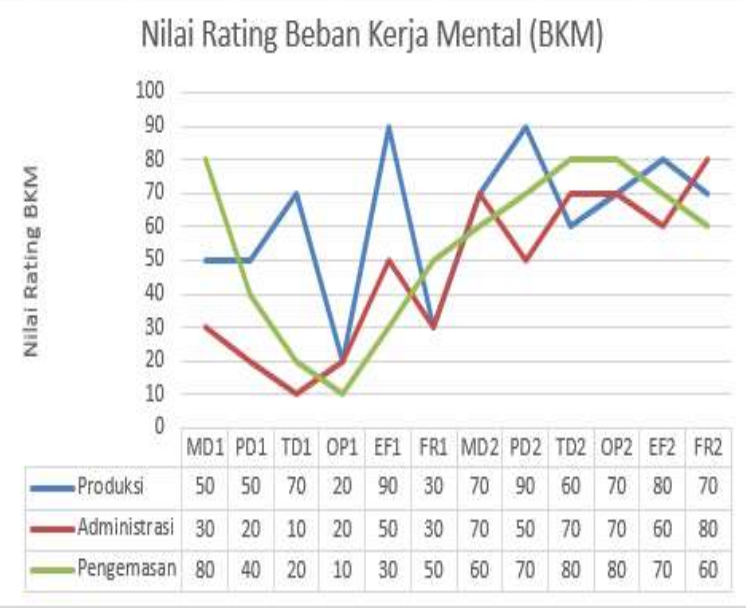

Berdasarkan data kuesioner, Nilai Produk didapatkan data sebagai berikut (Tabel 3). Berdasarkan data kuesioner, Nilai Weighted Mental Workload (WWL) didapatkan data sebagai berikut (Tabel 4).

Tabel 4 WWL

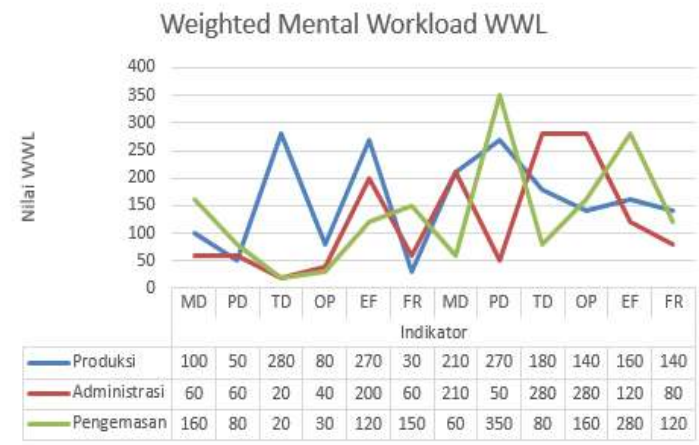


Tabel 6 WWL

\begin{tabular}{ccccc}
\hline Nilai Beban Kerja & Batik 1 & Kategori & Batik 2 & Kategori \\
\hline Produksi & 54 & Tinggi & 73,33 & Tinggi \\
Administrasi & 29,33 & Sedang & 68 & Tinggi \\
Pengemasan & 37,34 & Agak Tinggi & 70 & Tinggi \\
\hline
\end{tabular}

Tabel 7 Overall NASA-TLX

\begin{tabular}{ccccc}
\hline Nilai Beban Kerja & Batik 1 & Kategori & Batik 2 & Kategori \\
\hline Produksi & 54 & Tinggi & 73,33 & Tinggi \\
Administrasi & 29,33 & Sedang & 68 & Tinggi \\
Pengemasan & 37,34 & Agak Tinggi & 70 & Tinggi \\
\hline Total & 83,33 & & 211,33 & \\
Rata - rata & 41,67 & & 70,44 & \\
\hline
\end{tabular}

Berdasarkan data tersebut di atas, Nilai rata - rata untuk Weighted Mental Workload (WWL) di dapatkan data sebagai berikut (Tabel 5).

Tabel 5 WWL

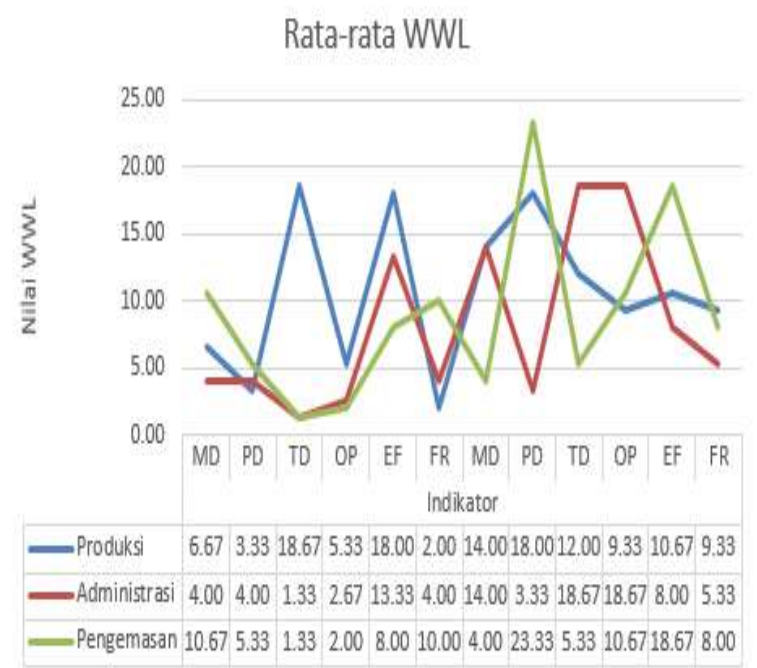

Berdasarkan data tersebut di atas, maka dapat diperoleh nilai BKM NASA-TLX untuk UKM Kreatif Batik 1 dan Batik 2 ditunjukkan pada tabel 6 .

Berdasarkan data keseluruhan UKM Industri Kreatif, dapat terlihat bahwa variasi terdapat pada semua UKM. Nilai Skor untuk Beban Kerja Mental di UKM Industri Kreatif Batik 1 adalah sebesar 41.67, dan untuk UKM Batik 2 adalah sebesar 70.44. Data ditunjukkan pada tabel 7.

Berdasarkan perhitungan beban kerja mental yang dilakukan pada UKM Industri Kreatif Batik 1 didapatkan hasil bahwa beban kerja mental tertinggi adalah pada bagian produksi yaitu sebesar 54 itu berarti operator memiliki tingkat beban kerja mental tinggi. Kemudian di posisi kedua adalah bagian pengemasan dengan skor sebesar 37,34 dan yang paling rendah adalah operator bagian administrasi sebesar 37,34. Hal ini disebabkan oleh pekerjaan di bidang produksi memiliki tingkat pekerjaan dengan ketelitian yang tinggi dibandingkan dengan bagian administrasi dan bagian pengemasan. Faktor dominan yang diakibatkan dari beban kerja yang tinggi pada operator bagian produksi adalah Temporal Demand (TD) atau waktu yang dibutuhkan untuk menyelesaikan suatu pekerjaan yaitu sebesar 18,67. Faktor dominan yang diakibatkan dari beban kerja yang agak tinggi pada operator bagian pengemasan adalah faktor Mental Demand (MD) atau aktifitas mental dalam menyelesaikan suatu pekerjaan yaitu 
sebesar 10,67. Faktor dominan yang diakibatkan dari beban kerja yang sedang pada operator bagian administrasi adalah Faktor Effort (EF) atau besar usaha baik mental dan fisik yang dibutuhkan untuk menyelesaikan pekerjaan (Astuti, et al., 2013), yaitu sebesar 13,34.

Berdasarkan perhitungan beban kerja mental yang dilakukan pada UKM Industri Kreatif Batik 2 terdapat perbedaan untuk masing - masing jenis pekerjaan. Nilai untuk pekerjaan administratif adalah 68 dan diklasifikasikan sebagai beban kerja mental yang tinggi, pekerjaan produksi mempunyai nilai 73.33 sehingga diklasifikasikan menjadi beban kerja mental yang tinggi juga. Adapun demikian pula dengan pekerjaan pengemasan, nilai beban kerja mental NASA-TLX nya adalah sebesar 70 yang juga di klasifikasikan sebagai beban kerja mental yang tinggi. Oleh karena itu, dapat diartikan bahwa semua tipe pekerjaan adalah mempunyai klasifikasi beban kerja mental yang tinggi, dan yang tertinggi nilainya adalah pada pekerjaan produki. Rata - rata tertinggi untuk WWL pada pekerjaan produksi adalah pada Physical Demand atau Kebutuhan Fisik. Terdapat beberapa kemungkinan / faktor yang dapat menyebabkan tingginya nilai NASA-TLX dari pekerjaan produksi. Faktor pertama adalah kondisi fisik dari operator yang menurun dan usia pekerja yang lebih tua melebihi para pekerja yang melakukan pekerjaan lain (dalam hal ini 43 tahun). Faktor berikutnya adalah bahwa pekerja dikondisikan untuk tetap berada dalam sebuah posisi diam (dalam menggambar batik) dalam durasi waktu yang lama dengan tingkat konsentrasi yang tinggi.

Faktor yang paling dominan dalam beban kerja mental ini adalah faktor internal yaitu faktor somatis yang berupa jenis kelamin. Berdasarkan jenis kelamin dari ketiga operator tersebut, operator bagian produksi merupakan operator yang memiliki jenis kelamin perempuan. Menurut hasil penelitian, operator perlu mendapatkan penanganan agar tidak terjadi stress. Rekomendasi yang kami berikan adalah dengan rekreasi atau refreshing secara berkala ke tempat - tempat yang menyenangkan agar fikiran menjadi fresh kembali dan agar dapat meminimalisir terjadinya stress. Penambahan karyawan juga perlu dilakukan mengingat, sebagai contoh di UKM Batik 1 tersebut hanya memiliki 3 orang karyawan, seharusnya ada tambahan karyawan terutama pada bidang produksi. Agar beban kerja mental dapat berkurang. Penambahan karyawan dilakukan agar beban kerja baik secara fisik maupun mental yang dirasakan setiap pekerja tidak melebihi dari batas yang telah ditentukan (Ramadhan, et al., 2014).

\section{KESIMPULAN DAN SARAN}

\subsection{Kesimpulan}

Berdasarkan hasil penelitian didapatkan kesimpulan sebagai berikut :

a. Nilai beban kerja mental industri kreatif batik adalah sebesar 41.67 (UKM Batik 1) dan 70.44 (UKM Batik 2).

b. Beban kerja mental ketiga tipe pekerjaan tersebut untuk kedua industri kreatif sangat beragam, namun secara overall dalam keadaan tinggi, hanya sebagian kecil yang bernilai sedang. Untuk nilai tertinggi beban kerja mentalnya adalah pada pekerjaan produksi di UKM Industri Kreatif Batik 2.

\subsection{Saran}

Dari hasil diskusi dalam penelitian ini, terdapat beberapa rekomendasi yang disarankan untuk mencegah pekerja dari beban kerja mental yang berlebih (overload), rekomendasinya adalah sebagai berikut :

a. Terdapat rekreasi atau refreshing secara berkala.

b. Penambahan jumlah karyawan sehingga beban kerjanya seimbang dan sesuai.

c. Pengaturan pola jam kerja-istirahat yang sesuai.

d. Meningkatkan ketrampilan para pekerja dan disesuaikan dengan peningkatan teknologi yang memudahkan pekerja melakukan pekerjaannya. 
e. Untuk penelitian selanjutnya, hasil dari penelitian ini dapat digunakan sebagai dasar untuk melakukan perbaikan desain sistem kerja yang memudahkan pekerja dan membuat stasiun kerja, waktu kerja dan sebagainya menjadi lebih ergonomis.

\section{DAFTAR PUSTAKA}

Arsi, R.M. and Partiwi, S.G. Analisis Beban Kerja untuk Menentukan Jumlah Optimal Karyawan dan Pemetaan Kompetensi Karyawan Berdasar Pada Job Description (Studi Kasus: Jurusan Teknik Industri, ITS, Surabaya). Jurnal Teknik ITS, 1(1), pp.A526-A529. ISSN: 2301-9271. 526-529, 2012.

Astuty, M.S., Wahyuning, C.S. and Yuniar, Y. Tingkat Beban Kerja Mental Masinis berdasarkan NASA-TLX (Task Load Index) di PT. KAI Daop. II Bandung. REKA INTEGRA, I(1). ISSN: 23385081. 69-77, 2012.

De Waard, D. The measurement of drivers' mental workload. Netherlands: Groningen University, Traffic Research Center., 1996.

Hancock, P.A. and Meshkati, N.E. Human mental workload. North-Holland, 1988.

Hart, S.G. and Staveland, L.E, Development of NASA-TLX (Task Load Index): Results of empirical and theoretical research. Advances in psychology, 52, pp.139-183, 1988.

HendrawaN, B., M. Ansori, R. Hidayat,. Pengukuran dan Analisis Beban Kerja Pegawai Bandara Hang Nadim : 1-14, 2012. http://www.kemenperin.go.id/artikel/10159/

Perajin-dan-Pengusaha-Batik-Masih-

Senjang.

http://obsessionnews.com/devisa-terbesarindonesia-2019-dari-pariwisatal.

http://www.suara.com/bisnis/2016/10/03/194

113/ekspor-batik-indonesia-tahun-2015178-juta-dolar-as.

http://www.thejakartapost.com/life/2016/10/ 04/12-local-designers-participate-inbatik-fashion-week.html.

http://sukabumikota.kemenag.go.id/file/doku men/D001020.pdf.

Jex, H.R. Measuring mental workload: Problems, progress, and promises. Advances in Psychology, 52, pp.5-39., 1988.

Puspawardhani, E.H., Suryoputro, M.R., Sari, A.D., Kurnia, R.D., dan Purnomo H. Mental Workload Analysis Using NASA-TLX Method between Various Level of Work in Plastic Injection Division of Manufacturing Company. In Advances in Safety Management and Human Factors (pp. 311-319). Springer International Publishing, 2016.

Ramadhan, R., Tama, I.P. and Efranto, R.Y., Analisa Beban Kerja Dengan Menggunakan Work Sampling dan Nasa-Tlx untuk Menentukan Jumlah Operator (Studi Kasus: PT XYZ). Jurnal Rekayasa dan Manajemen Sistem Industri, 2(5), pp.p926-973, 2014.

Reid, G.B. and Nygren, T.E. The subjective workload assessment technique: A scaling procedure for measuring mental workload. Advances in psychology, 52, pp.185-218, 1988. 
Rubio, S., Díaz, E., Martín, J. and Puente, J.M. Evaluation of subjective mental workload: A comparison of SWAT, NASA $\square$ TLX, and workload profile methods. Applied Psychology, 53(1), pp.61-86, 2004.

Tarwaka, Solichul H, Bakri A, dan Sudiajeng Lilik. Ergonomi Untuk Kesehatan dan Keselamatan Kerja dan Produktivitas. UNIBA Press. Surakarta, 2004.

Zijlstra, F.R.H. Efficiency in work behaviour: A design approach for modern tools. TU Delft, Delft University of Technology, 1993.

Zijlstra, F. and Meijman, T., Het meten van mentale inspanning met behulp van een subjectieve methode (measurement of mental effort with a subjective method). Mentale belasting en werkstress. Een arbeidspsychologische benadering, pp.42-61, 1989.

Zijlstra, F.R.H. and Van Doorn, L. The construction of a scale to measure perceived effort. University of Technology, 1985. 